\title{
Morphological and Functional Analysis of Rat Hepatocyte Spheroids Generated on Poly(L-lactic acid) Polymer in a Pulsatile Flow Bioreactor
}

\author{
ÉVA TÖRÖK, M.D., Ph.D., ${ }^{1}$ CHRISTIAN VOGEL, M.D., ${ }^{1}$ MARC LÜTGEHETMANN, M.D., ${ }^{1}$ \\ PETER X. MA, Ph.D., ${ }^{2}$ MAURA DANDRI, Ph.D., ${ }^{3}$ JOERG PETERSEN, M.D., ${ }^{3}$ \\ MARTIN R. BURDA, Ph.D., ${ }^{3}$ KLAUS SIEBERT, ${ }^{4}$ JOCHEN DÜLLMANN, M.D., ${ }^{4}$ \\ XAVIER ROGIERS, M.D., ${ }^{1}$ and JOERG-M. POLLOK, M.D., Ph.D. ${ }^{1}$
}

\begin{abstract}
Liver neo-tissue suitable for transplantation has not been established. Primary rat hepatocytes were cultured on three-dimensional biodegradable polymer matrices in a pulsatile flow bioreactor with the intention of inducing tissue formation and improving cell survival. Functional and structural analysis of the hepatocytes forming liver neo-tissue was performed. Biodegradable poly(L-lactic acid) (PLLA) polymer discs were seeded with $4 \times 10^{6}$ primary rat hepatocytes each, were exposed to a pulsatile medium flow of $24 \mathrm{~mL} / \mathrm{min}$ for 1, 2, 4, or 6 days and were investigated for monoethylglycinexylidine (MEGX) formation, ammonia detoxification, Cytokeratin 18 (CK18) expression, and preserved glycogen storage. Fine structural details were obtained using scanning and transmission electron microscopy. Spheroids of viable hepatocytes were formed. MEGX-specific production was maintained and ammonia removal capacity remained high during the entire flow-culture period of 6 days. CK18 distribution was normal. Periodicacid-Schiff reaction demonstrated homogenous glycogen storage. The hepatocytes reassembled to form intercellular junctions and bile canaliculi. Functional and morphological analysis of rat hepatocytes forming spheroids in a pulsatile flow bioreactor indicated preserved and intact hepatocyte morphology and specific function. Pulsatile flow culture on PLLA scaffolds is a promising new method of hepatic tissue engineering leading to liver neo-tissue formation.
\end{abstract}

\section{INTRODUCTION}

$\mathbf{T}$ HE LIVER HAS AN IMPRESSIVE REGENERATIVE POTENTIAL, as we know from clinical and experimental observations. ${ }^{1,2}$ Approximately $15-25 \%$ of patients with acute liver failure have a chance for spontaneous recovery. ${ }^{3}$ In modern liver surgery, up to $70 \%$ of the liver can be resected and will grow back to the original size within months. ${ }^{4,5}$

The excellent regenerative potential of liver cells has been the motivation for numerous researchers to focus on hepatocyte transplantation in the last decades. Next to liver transplantation, the transplantation of a sufficient number of

\footnotetext{
${ }^{1}$ Department of Hepatobiliary Surgery and Visceral Transplantation, University Medical Center Hamburg-Eppendorf, Hamburg, Germany.

${ }^{2}$ Department of Biologic and Materials Sciences, University of Michigan, Ann Arbor, Michigan.

${ }^{3}$ Department of Internal Medicine I, University Medical Center Hamburg-Eppendorf, Hamburg, Germany.

${ }^{4}$ Institute for Neuroanatomy, University Medical Center Hamburg-Eppendorf, Hamburg, Germany.

Presented in part at the 56th Annual Congress of Japanese Society for Gastroenterological Surgery, Akita, Japan, July 2001 and in abstract form in The Japanese Journal of Gastroenterological Surgery 34, 185, 2001, and received the JSGS 2001 Akita Award of the Japanese Society for Gastroenterological Surgery.
} 
hepatocytes may offer a valuable therapeutical approach for patients with liver-based metabolic defects and for patients with fulminant hepatic failure.

Vacanti and Langer proposed a strategy to deliver hepatocytes into the recipient using biodegradable polymers as a scaffold, ${ }^{6,7}$ thereby applying the principles and methods of tissue engineering. ${ }^{8-10}$ This method allows the transplantation of a large cell volume after seeding on a polymer scaffold. ${ }^{11}$ Highly porous polymer scaffolds provide sufficient space and protection for the hepatocytes to attach and permit oxygenation. Their three-dimensional structure helps the hepatocytes to reorganize into a configuration similar to their native environment and would allow vascular ingrowth. The scaffold is needed only during the initial period of tissue formation. Thereafter the polymer degrades via hydrolysis. $^{12}$

Many investigators have observed spheroidal formation of cultured hepatocytes, which is thought to be advantageous for several reasons. Such aggregated hepatocytes have proven to have better resistance to chemical and radiation stress and have shown higher levels of differentiated metabolic functions than monolayer hepatocyte cultures. ${ }^{13-19}$

We adapted a hepatocyte transplantation model using hepatocytes seeded onto a biodegradable polymer matrix. ${ }^{20-22}$ To improve survival and function of hepatocytes under shear stress conditions similar to an in vivo setting, we induced the formation of spheroidal aggregates (spheroids) in a pulsatile flow bioreactor. ${ }^{23-25}$ Our hypothesis was that flow bioreactor culture conditions for hepatocytes on biodegradable polymer matrices would improve hepatocyte survival and metabolic function after transplantation. In the present study we analyzed the functional and morphological characteristics of spheroid-forming hepatocytes. For this purpose, specific enzyme function analysis such as ammonia removal and monoethylglycinexylidide (MEGX) formation, Cytokeratin 18 (CK18) immunohistochemistry, and Periodic-acid-Schiff (PAS) staining, as well as scanning and transmission electron microscopy, were used.

\section{MATERIALS AND METHODS}

\section{Polymer fabrication}

Poly(L-lactic acid) (PLLA) polymer discs with 95\% porosity were fabricated as previously described. ${ }^{24,26,27}$ Polymers were manufactured to dimensions of $18 \mathrm{~mm}$ diameter and $1 \mathrm{~mm}$ thickness, with a pore size of 200 to $400 \mu \mathrm{m}$, and then cold-gas sterilized with ethylene oxide (H.W. Anderson Products, Chapel Hill, NC) before use.

\section{Hepatocyte isolation}

Adult, male, in-bred Lewis rats weighing between 200 and $300 \mathrm{~g}$ were used in all experiments (Charles River, Sulzfeld, Germany). The animals were housed in the Animal Research Facility of the University Medical Center Ham-
burg-Eppendorf, Germany, in accordance with the German national guidelines for the care of laboratory animals (Deutsches Tierschutzgesetz). Animals were given access to rat chow (Altromin Standard, Altromin, Hamburg, Germany) and water ad libitum and were maintained in 12-h light/dark cycles. Hepatocytes were isolated using a twostep collagenase digestion as previously described, using the original method of Seglen ${ }^{28}$ and modification of Aiken et al. ${ }^{29}$ The extracellular matrix was digested using a $0.025 \%$ collagenase solution (Collagenase type 2, Worthington, CellSystems Biotechnologie, St. Katharinen, Germany). Hepatocyte number and viability were determined using trypan blue exclusion.

\section{Polymer seeding}

Polymers were homogeneously seeded with $400 \mu \mathrm{L}$ of hepatocyte suspension containing $4 \times 10^{6}$ cells. The entire seeding procedure was performed on ice. We allowed the hepatocytes to attach for $20 \mathrm{~min}$.

\section{Culture medium}

Hepatocytes on polymer constructs were cultured in serumfree Williams' Medium E without L-glutamine (Gibco BRL) supplemented with $2 \mathrm{mM} \mathrm{N}$-acetyl-L-alanyl-L-glutamine (Biochrom, Berlin, Germany), 20 mM HEPES buffer (Biochrom), $4 \mu \mathrm{g} / \mathrm{mL}$ insulin (Gibco BRL), $1 \mathrm{mM}$ sodium pyruvate (Gibco BRL), $5 \mathrm{nM}$ dexamethasone (Sigma, St. Louis, MO), $10 \mathrm{ng} / \mathrm{mL}$ epidermal growth factor (Gibco BRL), and $1 \%$ penicillin/streptomycin (Biochrom).

\section{Culture conditions}

Polymer constructs $(n=32)$ with hepatocytes were secured perpendicular to the flow vector in a modified Cellmax Quad system (Cellco, Germantown, MD) as previously described. $^{23}$ One construct each per culture system was exposed to $24 \mathrm{~mL} / \mathrm{min}$ of pulsatile flow. Culture medium was pumped from a $265 \mathrm{~mL}$ reservoir using a Cellmax Quad pump apparatus (Cellco). Medium was recirculated back to the reservoir after passing through the culture chamber. The silicon tubing connecting the culture chamber with the medium reservoir allowed for gas exchange. All cultures were performed at $37^{\circ} \mathrm{C}$ with $5 \%$ carbon dioxide supplementation inside an incubator. The tissue engineered cellpolymer constructs were harvested after 1, 2, 4, or 6 days in culture.

\section{Specimen analysis}

After stopping the medium flow, cell-polymer constructs were removed from the flow chamber of the bioreactor and transferred into polystyrene culture dishes for viewing by phase-contrast microscopy (Olympus IX 50, Hamburg, Germany) before further investigation or fixation. Culture medium was sampled for analysis. 


\section{Lidocaine-MEGX test}

At the end of each culture period the hepatocyte-polymer specimens were cut in half, transferred onto a culture dish, and incubated with $3 \mathrm{~mL}$ of a $0.24 \mathrm{mg} / \mathrm{mL}(\mathrm{w} / \mathrm{v})$ solution of lidocaine/supplemented Williams' E culture medium at $37^{\circ} \mathrm{C}$ for $30 \mathrm{~min}$. The quantity of MEGX was measured using a TDxFLx fluorescencepolarization system using a MEGX assay (Abbott Laboratories, Abbott Park, IL).

\section{Ammonia removal}

At the end of the culture period the hepatocyte-polymer constructs were cut in half, transferred to a culture dish, and incubated with $10 \mathrm{~mL}$ supplemented Williams' Medium E additionally containing $0.5 \mathrm{mM}$ ammonium chloride. After incubation at $37^{\circ} \mathrm{C}$ for 2 and $4 \mathrm{~h}$, the ammonia concentration in the medium was measured using an indophenol method (Ammonia, Wako Chemicals, Neuss, Germany). The color reaction was measured at $630 \mathrm{~nm}$ using spectrophotometry (UV-160A Spectrophotometer, Shimadzu, Duisburg). ${ }^{30,31}$

\section{CK18 immunohistochemistry}

Immunohistochemical staining to demonstrate CK18 was performed on cryopreserved sections $(6 \mu \mathrm{m})$ of the hepatocyte spheroid specimens using the ABC method (Vectastain ABC-Kit, Vector, Burlingame, Canada). Specimens were fixed in acetone at $-20^{\circ} \mathrm{C}$ for $4 \mathrm{~min}$. A mouse anti-human anti-CK18 immunoglobulin $\mathrm{G}$ ( $\mathrm{IgG})$ antibody was used as primary antibody (1:50) (Progen, Heidelberg, Germany), with incubation for $60 \mathrm{~min}$ at room temperature. Biotinylated anti-mouse $\operatorname{IgG}$ was used as secondary antibody (1:200), with incubation for $30 \mathrm{~min}$ at room temperature (Vector). After each step of the immunohistochemical reaction, three 2-min washing steps in phosphate buffered saline, $\mathrm{pH} 7.4$, were performed. Sections were counterstained with hematoxylin and mounted.

\section{PAS reaction}

PAS reaction was applied as described previously ${ }^{32}$ to demonstrate glycogen content of rat hepatocyte-forming spheroids at every time point during the culture period. The intensity of the PAS reaction of the cultured hepatocytes forming spheroids was compared with standard rat liver sections.

\section{Scanning and transmission electron microscopy}

For scanning and transmission electron microscopy, the polymer-spheroid specimens were fixed at $4^{\circ} \mathrm{C}$ in $3 \%$ glutaraldehyde in $0.1 \mathrm{M}$ phosphate buffer. Specimens were washed with $0.1 \mathrm{M}$ phosphate-saccharose overnight and postfixed with $1 \%$ osmium tetroxide in $0.1 \mathrm{M}$ phosphatesaccharose. Specimens were dehydrated through graded series $(35-100 \%)$ of ethanol.
For scanning electron microscopy, prepared specimens were dried using a critical point dryer and placed on mounting studs. The mounted specimens were coated with gold on a sputter coater (BioRad, SEM Coating System, Richmond, CA). The coated specimens were stored in a desiccator until time of viewing under the scanning electron microscope (Zeiss DSM 940, Oberkochen, Germany).

For transmission electron microscopy, to extract the hepatocyte spheroids from the polymer scaffold, the following procedure was performed. The prepared specimens were incubated twice for $10 \mathrm{~min}$ in propylene oxide at $4{ }^{\circ} \mathrm{C}$, followed by 5 min centrifugation at $1500 \mathrm{rpm}$; then the supernatant was removed. The pellet was incubated for $1 \mathrm{~h}$ in a 1:1 (v/v) mixture of Epon (Serva, Heidelberg, Germany) and propylene oxide, followed by centrifugation. This procedure was repeated using an incubation in 1:3 (v/v) Epon/ propylene oxide and then in $100 \%$ Epon and subsequently polymerized for $24 \mathrm{~h}$ at $60^{\circ} \mathrm{C}$. The polymerized samples underwent ultrathin sectioning with Ultracut $\mathrm{E}$ (ReichertJung, Heidelberg, Germany), were stained with uranyl acetate and lead citrate, and were then viewed under a transmission electron microscope (Philips CM 100, Kassel, Germany).

\section{RESULTS}

\section{Spheroid formation in flow bioreactor}

Freshly isolated primary rat hepatocytes with a viability of more than $85 \%$ were seeded on highly porous polymer scaffolds and cultured in a pulsatile flow bioreactor. After 1 , 2,4 , or 6 days, the hepatocyte-polymer constructs were removed from the culture system and analyzed under phasecontrast microscopy. Already after 1 day, hepatocytes formed tightly packed cellular aggregates with smooth boundaries. These spherical-shaped aggregates, called spheroids, had a diameter ranging from 50 to $300 \mu \mathrm{m} .{ }^{25}$

\section{Lidocaine-MEGX test}

Cytochrome P450, usually present in hepatocytes, catalyzes the biotransformation of a wide variety of xenobiotics. ${ }^{33}$ The P450 enzyme activity of hepatocyte spheroids cultured in a flow bioreactor was determined in vitro by their ability to transform lidocaine to its metabolite MEGX. This test measures the activity of the most important P450 isoenzyme, CYP3A2, as well as CYP2B1. Lidocaine was exogenously added, and its degradation to the metabolic product, MEGX, was measured. The MEGX production would correlate with the metabolic activity of the hepatocytes in spheroids. Indeed, MEGX production was maintained at relatively constant rates during the 6 days of flow culture and varied between $14.28 \pm 2.86 \mathrm{ng} / \mathrm{mL} / 30 \mathrm{~min}$ and $23.13 \pm 4.63 \mathrm{ng} / \mathrm{mL} / 30 \mathrm{~min}$ (Fig. 1). This was calculated to the range of $1.03 \pm 0.21 \mu \mathrm{g} / \mathrm{d} / 10^{6}$ cells to $1.66 \pm$ $0.33 \mu \mathrm{g} / \mathrm{d} / 10^{6}$ cells. 


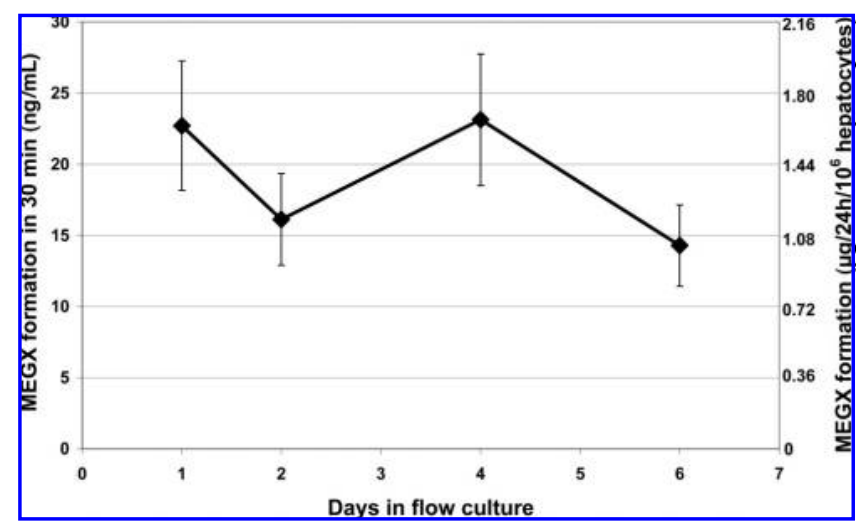

FIG. 1. The hepatocyte-seeded poly(L-lactic acid) discs were extracted from the flow bioreactor on Days 1, 2, 4, or 6; transferred into a culture dish; and cut in half. After exposure to $10 \mathrm{~mL}$ of $0.24 \mathrm{mg} / \mathrm{mL}(\mathrm{w} / \mathrm{v})$ lidocaine in Williams' Medium E for $30 \mathrm{~min}$, the monoethylglycinexylidine (MEGX) concentration was measured. For better comparison with data from the literature, the MEGX formation was also calculated and displayed in $\mu \mathrm{g} / 24 \mathrm{~h} / 10^{6}$ hepatocytes on the right y-axis.

\section{Ammonia removal}

Ammonia metabolism is an important differentiated metabolic function of hepatocytes. To evaluate the ammonia detoxification capacity of the hepatocyte spheroids, hepatocyte-polymer specimens were exposed to exogenous ammonia after they were removed from the bioreactor. The elimination rate of ammonia from the culture medium was determined after 2 and $4 \mathrm{~h}$ of incubation. The reduction in ammonia concentration within the first $4 \mathrm{~h}$ of exposure approximately doubled the rate after $2 \mathrm{~h}$ with the two curves

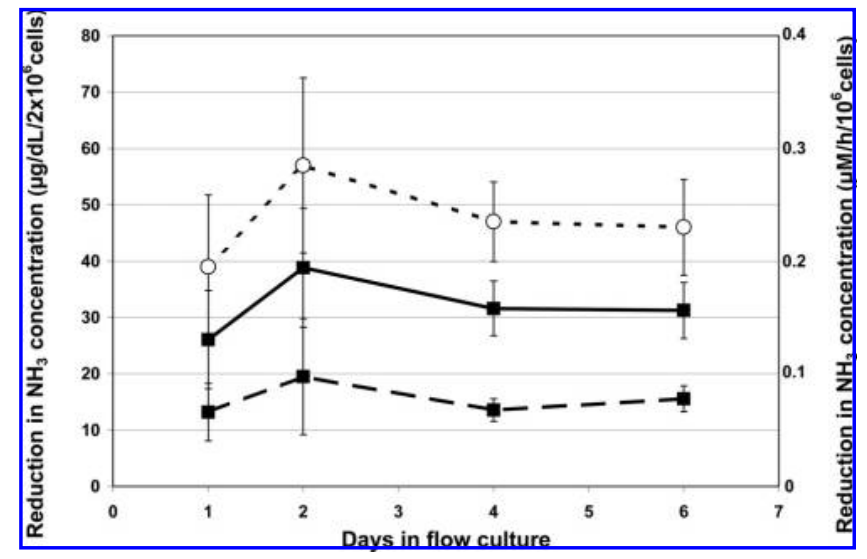

FIG. 2. The hepatocyte-seeded poly(L-lactic acid) discs were extracted from the flow bioreactor on Days 1, 2, 4, or 6; transferred into a culture dish; and cut in half. After exposure to $0.5 \mathrm{mM}$ ammonia $\left(\mathrm{NH}_{3}\right)$, the reduction of the $\mathrm{NH}_{3}$ concentration was measured using spectrophotometry, - - $\mathbf{\square}$ - - displaying the values $2 \mathrm{~h}$ after ammonia exposure, - $-4 \mathrm{~h}$ after ammonia exposure, and - - o - - calculated to $\mu \mathrm{M} / \mathrm{h} / 10^{6}$ cells (right y-axis) $4 \mathrm{~h}$ after ammonia exposure. running parallel (Fig. 2). The ammonia removal capacity of the hepatocytes in the spheroids was maintained constantly during the entire culture period of 6 days. The values ranged between $13.2 \pm 5.1$ and $19.5 \pm 10.3 \mu \mathrm{g} / \mathrm{dL}$ after $2 \mathrm{~h}$ of ammonia exposure and between $26.0 \pm 8.7$ and $38.8 \pm 10.5 \mu \mathrm{g} /$ $\mathrm{dL}$ after $4 \mathrm{~h}$. The minimal value was observed on Day 1 and the maximum on Day 2. The ammonia detoxification rate was calculated in values of $\mu \mathrm{M} / \mathrm{h} / 10^{6}$ hepatocytes. It ranged from $0.195 \pm 0.064$ to $0.285 \pm 0.078 \mu \mathrm{M} / \mathrm{h} / 10^{6}$ hepatocytes.

\section{CK18 immunohistochemistry}

Cytokeratins are the most complex group within the intermediate filaments $(7-11 \mathrm{~nm}$ in diameter) of the cytoskeleton. ${ }^{34}$ Hepatocytes contain CK18. Immunohistochemical staining with anti-CK18 antibody demonstrated a strong signal for CK18 in the spheroid-forming hepatocytes during the entire culture period of 6 days (Fig. 3).

\section{PAS staining}

PAS staining revealed preserved glycogen storage in rat hepatocytes forming spheroids in the flow bioreactor at every observation time point. Purple reactions of similar intensity could be observed at Day 1, 2, 4, and 6. This corresponded with the color reaction of control rat liver section (Fig. 4).

\section{Scanning and transmission electron microscopy}

Scanning electron microscopy of spheroids under threedimensional culture conditions showed them within or

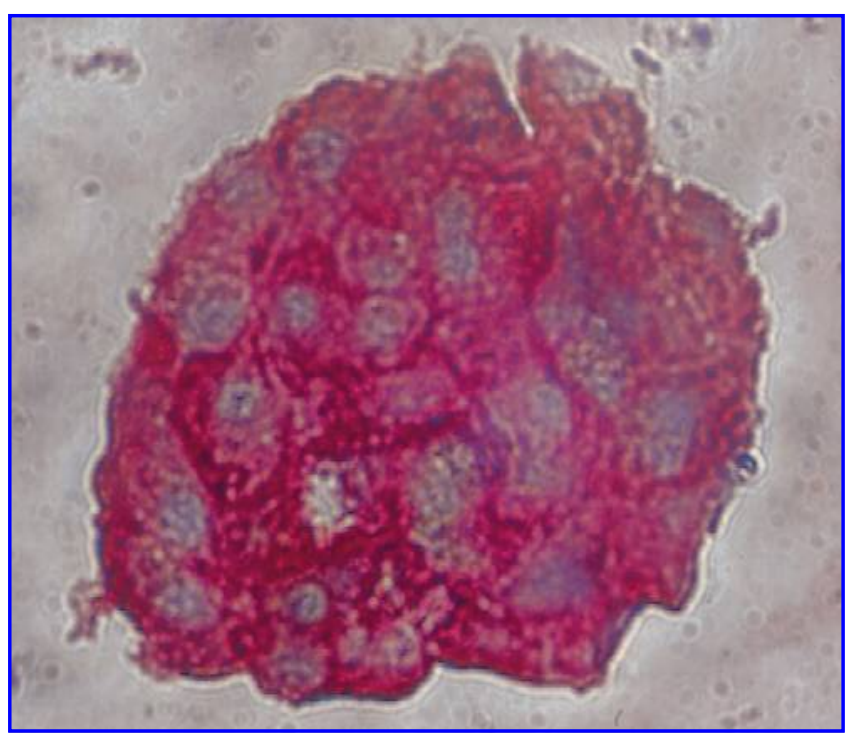

FIG. 3. Immunohistochemical staining for Cytokeratin 18 (CK18) demonstrated a strong signal for CK18, evenly distributed within the spheroid-forming hepatocytes, during the entire culture period. Shown is a section through a hepatocyte spheroid with a diameter of $130 \mu \mathrm{m}$ after 4 days in flow culture. (Color images available online at www.liebertpub.com/ten.) 


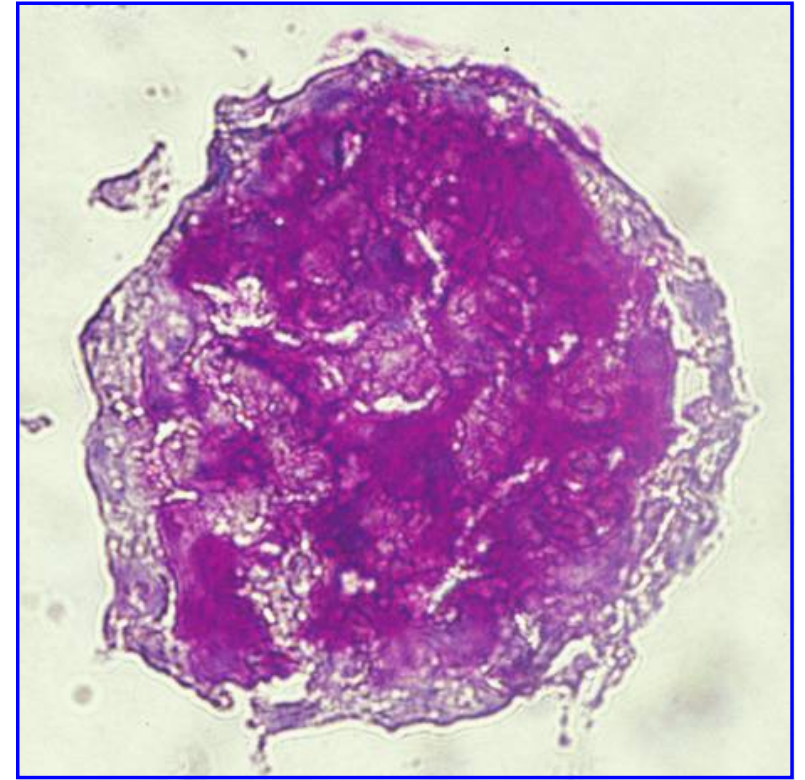

FIG. 4. Periodic-acid-Schiff staining revealed preserved glycogen production of the hepatocyte-forming spheroids in flow bioreactor culture. A purple reaction of similar intensity could be observed on Days 1, 2, 4 and 6. Shown is a section through a hepatocyte spheroid with a diameter of $200 \mu \mathrm{m}$ after 4 days in flow culture. (Color images available online at www.liebertpub.com/ten.) adjacent to the cubical chambers of the PLLA scaffold (Fig. 5). At higher magnification, the borders of individual hepatocytes and fine microvilli on their surface were recognizable. Holes and slits between hepatocytes on the surface of spheroids were found especially at the contact points of three hepatocytes.

Transmission electron microscopy of hepatocyte spheroids up to 6 days in flow culture revealed that the cellular elements of spheroidal aggregates showed the typical fine-structural characteristics of polarized and aggregated hepatocytes, including the formation of bile canaliculi with mature junctional complexes on both sides and lined by numerous microvilli (Fig. 6).

\section{DISCUSSION}

The scarcity of donor organs has become the biggest problem of liver transplantation worldwide. According to the Eurotransplant and United Network for Organ Sharingregistries, the number of newly registered patients is increasing every year. Although alternative transplantation methods such as living-related transplantation, ${ }^{35,36}$ or split liver transplantation, ${ }^{37,38}$ are increasingly applied, 363 patients died in 2002 in the Eurotransplant region while waiting for a liver transplant.

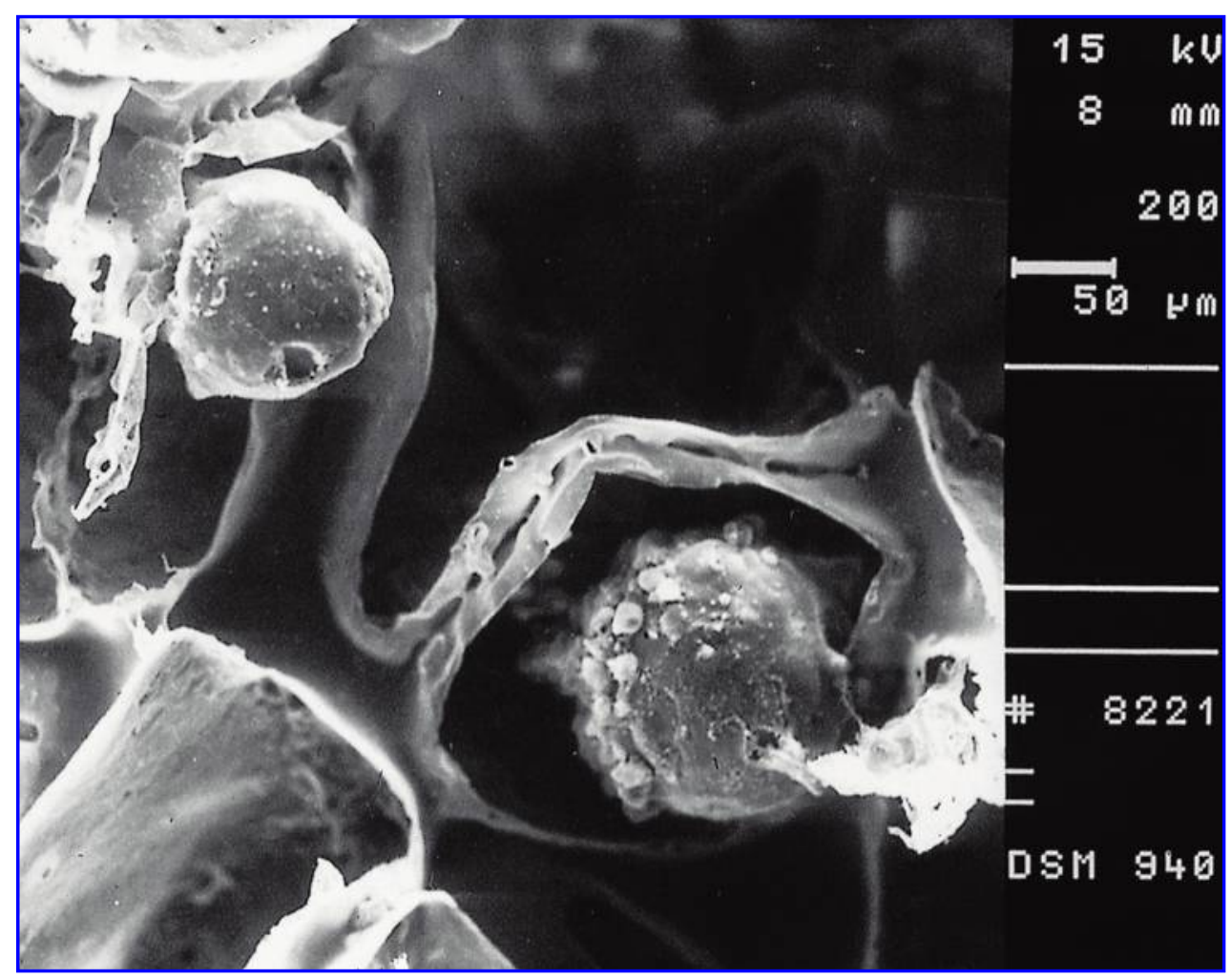

FIG. 5. Scanning electron micrograph of hepatocytes on a poly(L-lactic acid) (PLLA) polymer scaffold after 6 days in flow culture. Two spheroidal aggregates of hepatocytes can be seen within the cubical chambers of the PLLA polymer scaffold, with the larger spheroid measuring approximately $150 \mu \mathrm{m}$ in diameter. With higher magnification, the borders of individual hepatocytes can be discriminated. The fine stippling of the cell surface corresponds to numerous microvilli. 


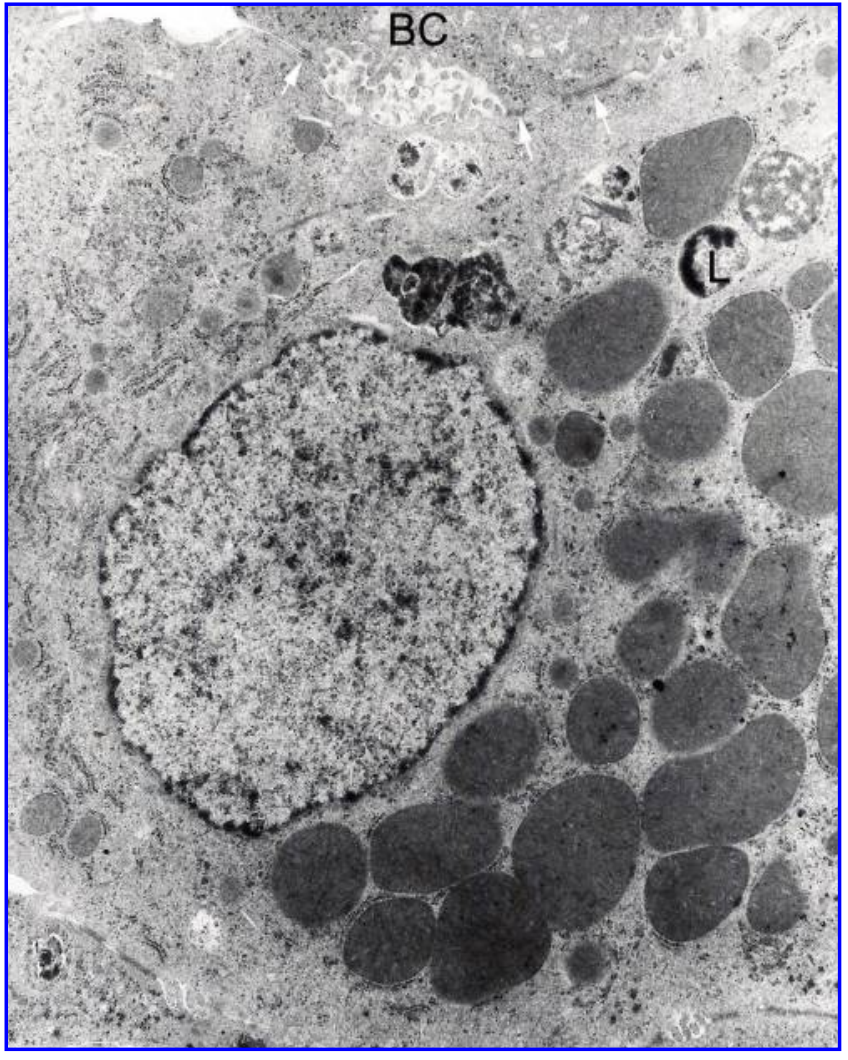

FIG. 6. Transmission electron micrograph of hepatocytes on a poly(L-lactic acid) polymer scaffold after 6 days in flow culture. Hepatocytes with numerous mitochondria and some lysosomes (L) can be seen. They form bile canaliculi (BC), which are sealed off by tight junctions on both sides, with their apical cell surface. A desmosome (macula adhaerens) invaginates the lateral cell surface and demarcates it from the basal cell surface. The basal cell surface is in a hepatocyte typical manner also equipped with microvilli.

Only 1263 liver transplants could be performed. ${ }^{39}$ The situation is similar in the United States. According to the Organ Procurement and Transplantation Network/Scientific Registry of Transplant Recipients 2003 Annual Report, 1818 patients died while waiting for a donor liver in 2002. The number of patients on the waiting list at the end of 2002 was 16,974, which represents an almost 6-fold increase over a period of ten years. ${ }^{40}$

Transplantation of hepatocytes may offer a valuable therapeutic approach for patients with liver-based metabolic defects and for patients with fulminant hepatic failure. Hepatocyte transplantation has the advantage over liver transplantation that the liver of the recipient remains in situ. In the case of the disease being a metabolic defect, the native liver continues to perform most of its functions. In the case of transient hepatic failure, the damaged liver may regain all its functions so that the transplanted hepatocytes are not permanently needed. Several problems of liver transplantation, such as vascular and biliary complications, or the side effects of long-term immunosuppressive medication could thereby be avoided. More patients could receive a treatment adapted to their particular liver disease by making better use of the available donor tissue or using part of their own liver as a cell source for the treatment of hepatocyte-based metabolic disorders after ex vivo gene therapy of their hepatocytes. A further promising cell-based treatment modality for liver failure and metabolic diseases is the administration of stem cells with in vivo or in vitro differentiation into metabolically active hepatocytes. If necessary, the option to perform a liver transplantation remains open. Hepatocyte transplantation could also complement liver transplantation, bridging the time until a suitable donor organ is available for a patient with acute liver failure.

Several methods to deliver hepatocytes into a recipient have been developed. Hepatocytes were injected into the splanchnic system (portal vein or spleen) or into various tissues or body cavities (dorsal fascia, peritoneum, omentum, pleural cavity). ${ }^{41-51}$ In a second approach, the hepatocytes were attached to microcarriers or larger polymer scaffolds. $6,11,23,52,53$

The optimal method to transplant hepatocytes has not been defined. A critical step of hepatocyte transplantation remains the engraftment of sufficient cell mass to achieve metabolic replacement. The major problem of the injection method is the restriction of the number of transplantable hepatocytes to approximately $5 \%$ of liver mass, because otherwise one runs the risk of inducing portal venous embolism or host tissue necrosis. Attachment of the hepatocytes to implantable scaffolds allows the number of transplantable hepatocytes to be increased up to a number of hepatocytes equivalent to the whole liver mass. ${ }^{11}$ The hepatocytes can be transplanted into vascularized areas of the body within a polymer scaffold and supplied with hepatotrophic factors from the portal circulation. ${ }^{20-22,54,55}$ The drawback of this method is the high initial cell loss directly after transplantation. ${ }^{56}$

Our laboratory and others have investigated heterotopic hepatocyte transplantation on biodegradable polymer matrices as an experimental treatment for liver diseases. $6,8,57,58$ It could be demonstrated that the surviving hepatocytes, transplanted on a polymer scaffold, can regenerate in situ up to 10 -fold. ${ }^{21}$

Applying in vitro methods of tissue engineering may provide a valuable tool to improve the matrix-attached hepatocyte or liver neo-tissue transplantation method. Conditioning the hepatocytes in three-dimensional culture within the polymer-matrix before implantation may result in better survival and functional status of the cells after transplantation.

Three-dimensional culture models could be beneficial for hepatocyte survival and preserved morphology and function. Hepatocyte morphology can be maintained by sandwiching the cells between two hydrated collagen layers ${ }^{59}$ or by stimulating them to form spheroidal aggregates. ${ }^{16-19,60,61} \mathrm{It}$ was proven that the extracellular matrix can regulate proliferation and differentiated functions of cultured hepatocytes. ${ }^{62,63}$ A critical test for the viability of hepatocytes in 
culture is the maintenance of good oxygen supply, as well as nutrition and waste removal. ${ }^{5,64}$

Consideration of these criteria led us to develop a pretransplantation culture system for hepatocytes, to come the closest to ideal hepatocyte transplantation conditions.

In a previous in vitro study, we were able to demonstrate spheroid formation of primary rat hepatocytes in a pulsatile flow bioreactor system with hepatocyte culture on a three-dimensional polymer scaffold ${ }^{23}$ and to optimize the pre-transplantation culture conditions of hepatocyte spheroids. $^{24,25}$

In the pulsatile flow bioreactor culture, primary rat hepatocytes preserved viability, morphology, and differentiated function as demonstrated by functional and structural analysis. We presume that the formation of spheroids is an advantageous configuration in improving the posttransplantation viability of hepatocytes. Generation of spheroids in static culture systems takes 3 to 7 days, ${ }^{14,60,65-71}$ although with dynamic culture systems, it takes only 1 to 2 days. ${ }^{15,23,72-78}$ Our culture system, using pulsatile flow of culture medium, imitates the physiologic situation of blood flow in the organism. ${ }^{23,75}$ With this special culture system, we achieved the formation of spheroidal hepatocyte aggregates within the first $24 \mathrm{~h}$. The vast majority (94\%) of spheroids were less than $200 \mu \mathrm{m}$ in diameter, and therefore, sufficient oxygen and nutrient supply was granted ${ }^{25}$ even to the cells in the center of the spheroids. ${ }^{79}$ We previously found that primary rat hepatocytes forming spheroids in a pulsatile flow bioreactor system consisted of viable hepatocytes, expressed active metabolic function, and preserved albumin production up to 6 days in culture. ${ }^{24,25}$

The purpose of our study was to analyze the specific functional and morphological characteristics of primary rat hepatocytes forming spheroids in more detail.

The liver is responsible for the vast majority of detoxification of foreign compounds. Lidocaine is an important marker of drug metabolism as a model substrate of phase 1 (oxidation, reduction, hydrolysis) metabolism and as a clinical index to estimate hepatic metabolic reserve capacity. Biotransformation of lidocaine requires cytochrome P450 enzyme function. ${ }^{33,70}$ Our results on MEGX formation as a result of lidocaine metabolism demonstrate that cytochrome P450 enzyme (CYP3A2, CYP2B1) function was preserved during the entire culture period. MEGX production, as an indicator of metabolically active hepatocytes in spheroids, ranged from $1.03 \pm 0.21 \mu \mathrm{g} / \mathrm{d} / 10^{6}$ cells to $1.66 \pm 0.33 \mu \mathrm{g} / \mathrm{d} / 10^{6}$ cells. These levels are in accordance with data $\left(1.2 \mu \mathrm{g} / \mathrm{d} / 10^{6}\right.$ cells $)$ from other investigators. ${ }^{80}$

Ammonia detoxification takes place in the mammalian liver and thus signals intact hepatocyte function. ${ }^{31} \mathrm{We}$ can conclude from our results that the ammonia detoxification, as a standard test for intact liver function, was maintained in primary rat hepatocytes forming spheroids in flow bioreactor culture during the entire culture period of 6 days. The comparison with previously reported data is difficult because of the diverse culture conditions and variability in the performance of the test. Nevertheless, the ammonia removal of our flow-cultured hepatocyte spheroids $(0.195 \pm 0.064$ to $0.285 \pm 0.078 \mu \mathrm{M} / 10^{6}$ hepatocytes), as measured without induction of the hepatocytes, correlates with the data reported by other investigators of spheroid culture systems, ${ }^{15,30,73,78}$ reaching from $0.168 \mu \mathrm{M} / \mathrm{h} / 10^{6}$ hepatocytes ${ }^{78}$ to $0.8 \mu \mathrm{M} / \mathrm{h} / 10^{6}$ hepatocytes ${ }^{15}$ with stimulating enzymeinducing agents.

CK18 can be found in many diverse simple epithelia. ${ }^{34,81,82,83}$ We found that the specific expression distribution of CK18 in the flow bioreactor-cultured hepatocytes was similar to normal rat liver tissue.

Glycogen storage in the hepatocytes plays a central role in glucose and energy metabolism of the organism. The positive PAS staining of the flow-cultured hepatocytes demonstrates their preserved ability to continue to specifically regulate glucose uptake and intracellular metabolism.

Scanning electron microscopy demonstrated spheroidalshaped cell aggregates covered by multiple microvilli on the surface, as a sign of metabolic and functional activity within the pores of the PLLA polymer scaffolds.

Transmission electron microscopy evaluation of the hepatocyte spheroids revealed that they were built up by aggregated hepatocyte-like cells joined by cell junctions. The cells were typically polarized to form bile canaliculi with their apical microvilli-bearing cell surface. The canaliculi were sealed off by tight junctions and were partially open to the surface of the spheroids. Such maintenance of polarized hepatocyte morphology had already been observed in spheroids of rat and porcine hepatocytes ${ }^{80,84}$ and in rat hepatocytes grown on collagen-coated polystyrene beads. ${ }^{85}$ In addition, the cells displayed coated pits and vesicles as a sign of receptor-mediated active micropinocytosisevidence of a specifically functioning vesicular transport mechanism.

One of the primary goals of tissue engineering is the maintenance of a high degree of cell viability and cellspecific function within the neo-tissue construct at time of implantation. In this study, we demonstrated that hepatocytes cultured on a biodegradable, highly porous PLLA polymer scaffold under pulsatile flow conditions maintained a high degree not only of viability, but also of hepatocytespecific functions, such as ammonia removal and cytochrome P450-dependent metabolism. The cells display normal distribution of the hepatocyte-specific cytoskeleton component CK18. The glucagon and energy metabolism remains intact, as demonstrated by positive PAS staining.

The primary hepatocytes reassemble in flow culture to form spheroidal organoids, and the cells reassume normal intercellular attachment and communication, including the formation of bile canaliculi between the apical membranes of adjacent cells.

Therefore, pre-cultivation of hepatocytes on a polymer scaffold with induction of metabolically active liver neotissue before implantation may offer an improvement for matrix-based hepatocyte transplantation. Unlike other 
spheroid-inducing culture systems, the hepatocyte spheroids are already cultured on their implantation vector (polymer scaffold), and no dissociation step is mandatory before implantation.

Our culture system could not only lead toward clinical application of a matrix-based liver neo-tissue implant, but could also serve as a three-dimensional culture model for applications in virology, toxicology, and drug development, in which metabolically active liver organoids could be more advantageous than monolayer hepatocyte cultures.

\section{ACKNOWLEDGMENTS}

The authors would like to thank the Werner-OttoFoundation for their support.

\section{REFERENCES}

1. Higgins, G.M., and Anderson, R.M. Experimental pathology of the liver. I. Restoration of the liver of the white rat following partial surgical removal. Arch Pathol 12, 186, 1931.

2. Laconi, S., Curreli, F., Diana, S., Pasciu, D., De Filippo, G., Sarma, D.S., Pani, P., and Laconi, E. Liver regeneration in response to partial hepatectomy in rats treated with retrorsine: a kinetic study. J Hepatology 31, 1069, 1999.

3. Bernuau, J., Rueff, B., and Benhamou, J. Fulminant and subfulminant hepatic failure: definition and cause. Sem Liver Dis 6, 97, 1986.

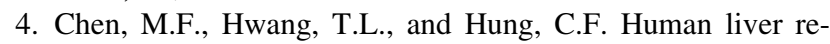
generation after major hepatectomy: a study of liver volume by computed tomography. Ann Surg 213, 227, 1991.

5. Selden, C., Jones, M., Wade, D., and Hodgson, H. Hepatotropin mRNA expression in human foetal liver development and in liver regeneration. FEBS Lett 270, 81, 1990.

6. Vacanti, J.P., Morse, M.A., Saltzman, W.M., Domb, A.J., Perez-Atayde, A., and Langer, R. Selective cell transplantation using bioabsorbable artificial polymers as matrices. J Pediatr Surg 23, 3, 1988.

7. Langer, R., Cima, L.G., Tamada, J.A., and Wintermantel, E. Future directions in biomaterials. Biomaterials 11, 738, 1990.

8. Langer, R., and Vacanti, J.P. Tissue engineering. Science 260, 920, 1993.

9. Mooney, D.J., and Mikos A.G. Growing new organs. Sci Am 280, 38, 1999.

10. Pollok, J.M., and Vacanti, J.P. Tissue engineering. Semin Ped Surg 5, 191, 1996.

11. Uyama, S., Kaufmann, P.M., Takeda, T., and Vacanti, J.P. Delivery of whole liver-equivalent hepatocyte mass using polymer devices and hepatotrophic stimulation. Transplantation 55, 932, 1993.

12. Hansen, L.K., and Vacanti, J.P. Hepatocyte transplantation using artificial biodegradable polymers. In: Hofman, M.A., ed. Current Controversies in Biliary Atresia. Austin, TX: Landes, RG, 1993, pp. 96-106.

13. Olive, P.L., and Durand, R.E. Drug and radiation resistance in spheroids: cell contact and kinetics. Cancer Metast Rev 13, 121, 1994.
14. Koide, N., Sakaguchi, K., Koide, Y., Asano, K., Kawaguchi, M., Matsushima, H., Takenami, T., Shinji, T., Mori, M., and Tsuji, T. Formation of multicellular spheroids composed of adult rat hepatocytes in dishes with positively charged surfaces and other nonadherent environments. Exp Cell Res 186, 227, 1990.

15. Kamihira, M., Yamada, K., Hamamoto, R., and Ijima, S. Spheroid formation of hepatocytes using synthetic polymer. Ann N Y Acad Sci 831, 398, 1997.

16. Dvir-Ginzberg, M., Elkayam, T., Aflalo, E.D., Agbaria, R., and Cohen, S. Ultrastructural and functional investigations of adult hepatocyte spheroids during in vitro cultivation. Tissue Eng 10, 1806, 2004.

17. Dvir-Ginzberg, M., Gamlieli-Bonshtein, I., Agbaria, R., and Cohen, S. Liver tissue engineering within alginate scaffolds: effects of cell-seeding density on hepatocyte viability, morphology, and function. Tissue Eng 9, 757, 2003.

18. Glicklis, R., Shapiro, L., Agbaria, R., Merchuk, J.C., and Cohen, S. Hepatocyte behavior within three-dimensional porous alginate scaffolds. Biotechnol Bioeng 67, 344, 2000.

19. Glicklis, R., Merchuk, J.C., and Cohen, S. Modeling mass transfer in hepatocyte spheroids via cell viability, spheroid size, and hepatocellular functions. Biotechnol Bioeng 86, 672, 2004.

20. Fontaine, M., Hansen, L.K., Thompson, S., Uyama, S., Ingber, D.E., Langer, R., and Vacanti, J.P. Transplantation of genetically altered hepatocytes using cell-polymer constructs. Transplant Proc 25, 1002, 1993.

21. Kneser, U., Kaufmann, P.M., Fiegel, H.C., Pollok, J.M., Kluth, D., Izbicki, J.R., Herbst, H., and Rogiers, X. Long-term differentiated function of heterotopically transplanted hepatocytes on three-dimensional polymer matrices. J Biomed Mater Res 47, 494, 1999.

22. Johnson, L.B., Aiken, J., Mooney, D., Schloo, B.L., GriffithCima, L., Langer, R., and Vacanti, J.P. The mesentery as a laminated vascular bed for hepatocyte transplantation. Cell Transplantation 3, 273, 1994.

23. Pollok, J.M., Kluth, D., Cusick, R.A., Lee, H., Utsunomiya, H., Ma, P.X., Langer, R., Broelsch, C.E., and Vacanti, J.P. Formation of spheroidal aggregates of hepatocytes on biodegradable polymers under continuous flow bioreactor conditions. Eur J Pediatr Surg 8, 195, 1998.

24. Török, É., Pollok, J.M., Ma, P.X., Kaufmann, P.M., Dandri, M., Petersen, J., Burda, M.R., Kluth, D., Perner, F., and Rogiers, X. Optimization of hepatocyte spheroid formation for hepatic tissue engineering on 3-dimensional biodegradable polymer within a flow bioreactor prior to implantation. $\underline{\text { Cells }}$ Tissues Organs 169, 34, 2001.

25. Török, É., Pollok, J.M., Ma, P.X., Vogel, C., Dandri, M., Petersen, J., Burda, M.R., Kaufmann, P.M., Kluth, D., and Rogiers, X. Hepatic tissue engineering on 3-dimensional biodegradable polymers within a pulsatile flow bioreactor. Digest Surg 18, 196, 2001.

26. Ma, P.X., and Langer, R. Fabrication of biodegradable polymer foams for cell transplantation and tissue engineering. In: Yarmush, M., and Morgan, J., eds. Tissue Engineering Methods and Protocols. Totowa, NJ: Humana Press Inc., 1999, pp. 47-56.

27. Ma, P.X., and Zhang, R. Synthetic nano-scale fibrous extracellular matrix. J Biomed Mat Res 46, 60, 1999. 
28. Seglen, P.O. Preparation of isolated rat liver cells. Methods Cell Biol 13, 29, 1976.

29. Aiken, J., Cima, L., Schloo, B., Mooney, D., Johnson, L., Langer, R., and Vacanti, J.P. Studies in rat liver perfusion for optimum harvest of hepatocytes. J Pediatr Surg 25, 140, 1990.

30. Lin, K.H., Maeda, S., and Saito, T. Long-term maintenance of liver-specific functions in three-dimensional culture of adult rat hepatocytes with porous gelatin sponge support. Biotechnol Appl Biochem 21, 19, 1995.

31. Häussinger, D., Steeb, R., Kaiser, S., Wettstein, M., Stoll, B., and Gerok, W. Nitrogen metabolism in normal and cirrhotic liver. Adv Exp Med Biol 272, 47, 1990.

32. Kneser, U., Kaufmann, P.M., Fiegel, H.C., Pollok, J.M., Kluth, D., Herbst, H., and Rogiers, X. Heterotopic hepatocyte transplantation utilizing pancreatic islet co-transplantation for hepatotrophic stimulation: morphologic and morphometric evaluation. Ped Surg Int 15, 168, 1999.

33. Niwa, T., Koide, N., Tsuji, T., Imaoka, S., Ishibashi, F., Funae, Y., and Katagiri, M. Cytochrome P450s of isolated rat hepatocytes in spheroid and monolayer cultures. Res Comm Mol Path Pharm 91, 372, 1996.

34. Moll, R., Franke, W.W., and Schiller, D.L. The catalog of human cytokeratins: patterns of expression in normal epithelia tumors and cultured cells. Cell 31, 11, 1982.

35. Broelsch, C.E., Whitington, P.F., Emond, J.C., Heffron, T.G., Thistlethwaite, J.R., Stevens L., Piper, J., Whitington, S.H., and Lichtor, J.L. Liver transplantation in children from living related donors: surgical techniques and results. Ann Surg 214, 428, 1991.

36. Levinski, N.G. Organ donation by unrelated donors. N Engl J Med 343, 430, 2000.

37. Rogiers, X., Malago, M., Gawad, K., Jauch, K.W., Olausson, M., Knoefel, W.T., Gundlach, M., Bassas, A., Fischer, L., Sterneck, M., Burdelski, M., and Broelsch, C.E. In situ splitting of cadaveric livers-the ultimate expansion of a limited donor pool. Ann Surg 224, 331, 1996.

38. Rogiers, X., Topp, S., and Broering, D.C. Split liver transplantation: split in-situ or ex-situ? Curr Opin Transplant 5, 57, 2000.

39. Annual Report, Eurotransplant International Foundation, 2002.

40. OPTN/SRTR 2003 Annual Report.

41. Holzman, M.D., Rozga, J., Neuzil, D.F., Griffin, D., Moscioni, A.D., and Demetriou, A.A. Selective intraportal hepatocyte transplantation in analbuminemic and Gunn rats. Transplantation 55, 1213, 1993.

42. Kusano, M., and Mito, M. Observations on the fine structure of long-survived isolated hepatocytes inoculated into rat spleen. Gastroenterology 82, 616, 1982.

43. Jirtle, R.L., Biles, C., and Michalopoulos, G. Morphologic and histochemical analysis of hepatocytes transplanted into syngeneic hosts. Am J Pathol 101, 115, 1980.

44. Demetriou, A.A., Reisner, A., Sanchez, J., Levenson, S.M., Moscioni, A.D., and Chowdhury, J.R. Transplantation of microcarrier-attached hepatocytes into $90 \%$ partially hepatectomized rats. Hepatology 8, 1006, 1988.

45. Henne-Bruns, D., Krüger, U., Sümpelmannn, D., Lierse, W., and Kremer, B. Intraperitoneal hepatocyte transplantation: morphological results. Virchows Archiv 419, 45, 1991.

46. Roger, V., Balladur, P., Honiger, J., Baudrimont, M., Delelo, R., Robert, A., Calmus, Y., Capeau, J., and Nordlinger, B.
Internal bioartificial liver with xenogeneic hepatocytes prevents death from acute liver failure: an experimental study. Ann Surg 228, 1, 1998.

47. Muraca, M., Neri, D., Parenti, A., Feltracco, P., Granato, A., Vilei, M.T., Ferraresso, C., Ballarin, R., Zanusso, G.E., Giron, G., Rozga, J., and Gerunda, G. Intraportal hepatocyte transplantation in the pig: a hemodynamic and histopathological study. Transplantation 73, 890, 2002.

48. Carraresi, L., Mora, M., Lazzeri, M., Orsini, E., Romagnoli, R., Comporti, M., Carli, A., Carmellini, M., and Rossigni, M. Hepatocyte grafting as an alternative to liver transplant. Transplant Proc 33, 3474, 2001.

49. Song, E., Chen, J., Su, F., Wang, M., and Heemann, U. Granzyme B. inhibitor I reduces apoptotic cell death of allogeneic-transplanted hepatocytes in spleen. Transplant Proc 33, 3274, 2001.

50. Dandri, M., Burda, M.R., Gocht, A., Török, É., Pollok, J.M., Rogler, C.E., Will, H., and Petersen, J. Woodchuck hepatocytes remain permissive for hepadnavirus infection and mouse liver repopulation after cryopreservation. Hepatology 34, 824, 2001.

51. Dandri, M., Burda, M.R., Török, É., Pollok, J.M., Iwanska, A., Sommer, G., Rogiers, X., Rogler, C.E., Gupta, S., Will, H., Greten, H., and Petersen, J. Repopulation of mouse liver with human hepatocytes and in vivo infection with hepatitis B virus. Hepatology 33, 981, 2001.

52. Mooney, D.J., Kaufmann, P.M., Sano, K., Schwendema, S.P., Majahod, K., Schloo, B., Vacanti, J.P., and Langer, R. Localized delivery of epidermal growth factor improves the survival of transplanted hepatocytes. Biotechnol Bioeng 50, 422, 1996.

53. Uyama, S., Kaufmann, P.M., Kneser, U., Fiegel, H.C., Pollok, J.M., Kluth, D., Vacanti, J.P., and Rogiers, X. Hepatocyte transplantation using biodegradable matrices in ascorbic aciddeficient rats: comparison with heterotopically transplanted liver grafts. Transplantation 71, 1226, 2001.

54. Mooney, D.J., Kaufmann, P.M., Sano, K., McNamara, K.M., Vacanti, J.P., and Langer, R. Transplantation of hepatocytes using porous, biodegradable sponges. Transplant Proc 26, 3425, 1994.

55. Kaihara, S., Borenstein, J., Koka, R., Lalan, S., Ochoa, E.R., Ravens, M., Pien, H., Cunningham, B., and Vacanti, J.P. Silicon micromachining to tissue engineer branched vascular channels for liver fabrication. Tissue Eng 6, 105, 2000.

56. Sano, K., Cusick, R.A., Lee, H., Pollok, J.M., Kaufmann, P.M., Uyama, S., Mooney, D., Langer, R., and Vacanti, J.P. Regenerative signals for heterotopic hepatocyte transplantation. Transplant Proc 28, 1857, 1996.

57. Gilbert, J.C., Takada, T., Stein, J.E., Langer, R., and Vacanti, J.P. Cell transplantation of genetically altered cells on biodegradable polymer scaffolds in syngeneic rats. Transplantation 56, 423, 1993.

58. Kaufmann, P.M., Fiegel, H.C., Kneser, U., Pollok, J.M., Kluth, D., and Rogiers, X. Influence of pancreatic islets on growth and differentiation of hepatocytes in co-culture. Tissue Eng 5, 583, 1999.

59. Dunn, J.C., Tompkins, R.G., and Yarmush, M.L. Long-term in vitro function of adult hepatocytes in a collagen sandwich configuration. Biotechnol Prog 7, 237, 1991.

60. Landry, B., Bernier, D., Ouellet, C., Gayety, R., and Marcia, N. Spheroidal aggregate of rat liver cells: histotypic 
reorganization, biomatrix deposition, and maintenance of functional activities. J Cell Biol 101, 914, 1985.

61. Koide, N., Shinji, T., Tanabe, T., Asano, K., Kawaguchi, M., Sakaguchi, K., Koide, Y., Mori, M., and Tsuji, T. Continued high albumin production by multicellular spheroids of adult rat hepatocytes formed in the presence of liver-derived proteoglycans. Biochem Biophys Res Co 161, 385, 1989.

62. Mooney, D., Hansen, L., Vacanti, J.P., Langer, R., Farmer, S., and Ingber, D. Switching from differentiation to growth in hepatocytes: control by extracellular matrix. J Cell Physiol 151, 497, 1992.

63. Block, G.D., Locker, J., Bowen, W.C., Petersen, B.E., Katyal, S., Strom, S.C., Riley, T., Howard, T.A., and Michalopoulos, G.K. Population expansion, clonal growth, and specific differentiation patterns in primary cultures of hepatocytes induced by HGF/SF, EGF, and TGF alpha in a chemically defined (HGM) medium. J Cell Biol 132, 1133, 1996.

64. Kim, S.S., Utsunomija, H., Koski, J.A., Wu, B.M., Cima, M.J., Sohn, J., Mukai, K., Griffith, L.G., and Vacanti, J.P. Survival and function of hepatocytes on a novel three-dimensional synthetic biodegradable polymer scaffold with an intrinsic network of channels. Ann Surg 228, 8, 1998.

65. Sakaguchi, K., Koide, N., Asano, K., Takabatake, H., Matsushima, H., Takenami, T., Ono, R., Sasaki, S., Mori, M., Koide, Y., and Tsuji, T. Promotion of spheroid assembly of adult rat hepatocytes by some factor(s) present in the initial 6hour conditioned medium of the primary culture. Pathobiology 59, 351, 1991.

66. Peshwa, M.V., Wu, F.J., Follstad, B.D., Cerra, F.B., and Hu, W.S. Kinetics of formation of hepatocyte spheroids. Biotechnol Prog 10, 460, 1994.

67. Shinji, T., Koide, N., and Tsuji, T. Glycosaminoglycans partially substitute for proteoglycans in spheroid formation of adult rat hepatocytes in primary culture. Cell Struct Funct 13, 179, 1988.

68. Ota, K., Saito, S., Hamasaki, K., Tanaka, N., and Orita, K. Transplantation of xenogeneic hepatocytes: three-dimensionally cultured hepatocyte (spheroid) transplantation into the spleen. Transplant Proc 28, 1430, 1996.

69. Okada, Y., Saito, S., Fujisawa, K., Yagi, T., and Tanaka, N. Does adenovirus-mediated viral IL-10 gene transfer prolong survival of xenogeneic spheroidal aggregate-cultured hepatocytes? Transplant Proc 32, 1021, 2000.

70. Tong, J.Z., De Lagausie, P., Furlan, V., Cresteil, T., Bernard, O., and Alvarez, F. Long-term culture of adult rat hepatocyte spheroids. Exp Cell Res 200, 326, 1992.

71. Gosnell, J.E., Wong, C.B., Kumwenda, Z.L., Welch, W.J., and Harris, H.W. Extracellular matrix regulates the hepatocellular heat shock response. J Surg Res 91, 43, 2000.

72. Kosaka, T., Tsuboi, S., Fukaya, K., Pu, H., Ohno, T., Tsuji, T., Miyazaki, M., and Namba, M. Spheroid cultures of human hepatoblastoma cells (HuH-6 Line) and their application for cytotoxicity assay of alcohols. Acta Med Okayama 50, 61, 1996.

73. Kan, P., Miyoshi, H., Yanagi, K., and Ohshima, N. Effects of shear stress on metabolic function of the co-culture system of hepatocyte/nonparenchymal cells for a bioartificial liver. ASAIO J 44, M441, 1998.
74. Vacanti, J.P., and Langer, R. Tissue engineering: the design and fabrication of living replacement devices for surgical reconstruction and transplantation. Lancet 354, 32, 1999.

75. Niklason, L.E., Gao, J., Abbott, W.M., Hirschi, K.K., Houser, S., Marini, R., and Langer, R. Functional arteries grown in vitro. Science 284, 489, 1999.

76. Enosawa, S., Miyashita, T., Suzuki, S., Li, X.K., Tsunoda, M., Amemiya, H., Yamanaka, M., Hiramatsu, S., Tanimura, N., Omasa, T., Suga, K., and Matsumura, T. Long-term culture of glutamine synthetase-transfected HepG2 cells in circulatory flow bioreactor for development of a bioartificial liver. $\underline{\text { Cell }}$ Transplant 9, 711, 2000.

77. Wu, F.J., Friend, J.R., Hsiao, C.C., Zilliox, M.J., Ko, W.J., Cerra, F.B., and Hu, W.S. Efficient assembly of rat hepatocyte spheroids for tissue engineering applications. Biotechnol Bioeng 50, 404, 1996.

78. Yamada, K., Kamihira, M., Hamamoto, R., and Iijima, S. Efficient induction of hepatocyte spheroids in a suspension culture using a water-soluble synthetic polymer as an artificial matrix. J Biochem 123, 1017, 1998.

79. Folkman, J., and Hochberg, M. Self-regulation of growth in three dimensions. J Exp Med 138, 745, 1973.

80. Lazar, A., Mann, H.J., Remmel, R.P., Shatford, R.A., Cerra, F.B., and Hu, W.S. Extended liver-specific functions of porcine hepatocyte spheroids entrapped in collagen gel. In Vitro Cell Dev Biol 31, 340, 1995.

81. Van Eyken, P., and Desmet, V.J. Cytokeratins and the liver. Liver 13, 113, 1993.

82. Franke, W.W., Schiller, D.L., Moll, R., Winter, S., Schmid, E., and Engelbrecht, I. Diversity of cytokeratins-differentiation specific expression of cytokeratin polypeptides in epithelial cells and tissues. J Mol Biol 153, 933, 1981.

83. Mitaka, T., Norioka, K.I., Nakamura, T., and Mochizuki, Y. Effects of mitogens and co-mitogens on the formation of small-cell colonies in primary cultures of rat hepatocytes. J Cell Physiol 157, 461, 1993.

84. Lazar, A., Peshwa, M.V., Wu, F.J., Chi, C.M., Cerra, F.B., and $\mathrm{Hu}$, W.S. Formation of porcine hepatocyte spheroids for use in a bioartificial liver. Cell Transplant 4, 259, 1995.

85. Michalopoulos, G.K., Bowen, W.C., Zajac, V.F., Beer-Stolz, D., Watkins, S., Kostrubsky, V., and Strom, S.C. Morphogenetic events in mixed cultures of rat hepatocytes and nonparenchymal cells maintained in biological matrices in the presence of hepatocyte growth factor and epidermal growth factor. Hepatology 29, 90, 1999.

Address reprint requests to: PD Dr. Dr. med. Jörg-Matthias Pollok Department of Hepatobiliary Surgery and Visceral Transplantation

University Medical Center Hamburg-Eppendorf Hamburg, Germany

E-mail: pollok@uke.uni-hamburg.de 
This article has been cited by:

1. Tammy T. Chang, Millie Hughes-Fulford . 2009. Monolayer and Spheroid Culture of Human Liver Hepatocellular Carcinoma Cell Line Cells Demonstrate Distinct Global Gene Expression Patterns and Functional PhenotypesMonolayer and Spheroid Culture of Human Liver Hepatocellular Carcinoma Cell Line Cells Demonstrate Distinct Global Gene Expression Patterns and Functional Phenotypes. Tissue Engineering Part A 15:3, 559-567. [Abstract] [Full Text] [PDF] [PDF Plus]

2. Ruei-Zhen Lin, Hwan-You Chang. 2008. Recent advances in three-dimensional multicellular spheroid culture for biomedical research. Biotechnology Journal 3:9-10, 1172-1184. [CrossRef]

3. Shusaku Tsukiyama, Michiaki Matsushita, Masaru Tanaka, Hitoshi Tamura, Satoru Todo, Sadaaki Yamamoto, Masatsugu Shimomura. 2008. Enhanced Cell Survival and Yield of Rat Small Hepatocytes by Honeycomb-Patterned Films. Japanese Journal of Applied Physics 47:No. 2, 1429-1434. [CrossRef] 